ARTICLE

https://doi.org/10.1038/s41467-020-15536-x

\title{
Hydrogen migration at restructuring palladium-silver oxide boundaries dramatically enhances reduction rate of silver oxide
}

\author{
Christopher R. O'Connor (iD ${ }^{1}$, Matthijs A. van Spronsen (i) ${ }^{1,2}$, Tobias Egle (iD ${ }^{3}$, Fang Xu (iD ${ }^{1}$, Heath R. Kersell ${ }^{2}$, \\ Judit Oliver-Meseguer ${ }^{2}$, Mustafa Karatok (D) ${ }^{1}$, Miquel Salmeron (10 ${ }^{2,4}$, Robert J. Madix ${ }^{3}$ \& \\ Cynthia M. Friend (10) $1,3 凶$
}

Heterogeneous catalysts are complex materials with multiple interfaces. A critical proposition in exploiting bifunctionality in alloy catalysts is to achieve surface migration across interfaces separating functionally dissimilar regions. Herein, we demonstrate the enhancement of more than $10^{4}$ in the rate of molecular hydrogen reduction of a silver surface oxide in the presence of palladium oxide compared to pure silver oxide resulting from the transfer of atomic hydrogen from palladium oxide islands onto the surrounding surface formed from oxidation of a palladium-silver alloy. The palladium-silver interface also dynamically restructures during reduction, resulting in silver-palladium intermixing. This study clearly demonstrates the migration of reaction intermediates and catalyst material across surface interfacial boundaries in alloys with a significant effect on surface reactivity, having broad implications for the catalytic function of bimetallic materials.

\footnotetext{
${ }^{1}$ Department of Chemistry and Chemical Biology, Harvard University, Cambridge, MA 02138, USA. ${ }^{2}$ Materials Sciences Division, Lawrence Berkeley Nationa Laboratory, 1 Cyclotron Road, Berkeley, CA 94720, USA. ${ }^{3}$ School of Engineering and Applied Sciences, Harvard University, Cambridge, MA 02138, USA.

${ }^{4}$ Department of Materials Science and Engineering, University of California, Berkeley, CA 94720, USA. ${ }^{凶}$ email: friend@fas.harvard.edu
} 
eterogeneous catalysts are complex materials that generally contain multiple interfaces which can modify the kinetics and selectivity for key reactions, especially for the production and use of molecular hydrogen for energy generation and chemical synthesis ${ }^{1-6}$. The increasing interest in alloy catalysts creates new challenges in understanding the effect of interfaces. Although interfaces between metal nanoparticles and the metal oxide support have been extensively investigated, less is known about interfaces that form on alloys themselves, independent of the support. Phase segregation on metallic alloy nanoparticles can form metal/metal interfaces primarily arising from differences in surface free energy of the metal components and unfavorable mixing enthalpies ${ }^{7-9}$. Under oxidizing conditions, complex metal/oxide and oxide/oxide interfaces can form by phase separation and surface segregation arising from differences in metal-oxygen bonding ${ }^{10,11}$. Therefore, a dynamic understanding of material restructuring and chemical behavior is
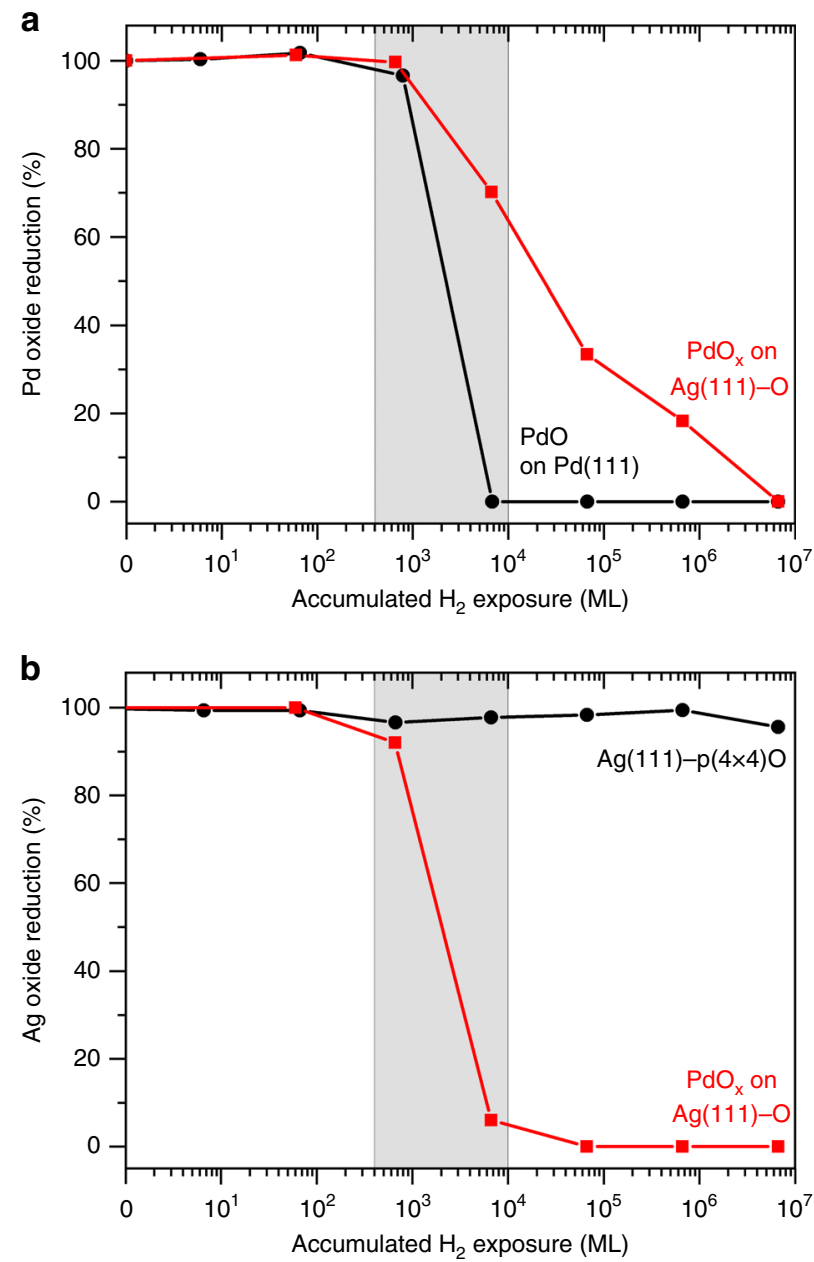

Fig. $1 \mathrm{Pd}$ oxide accelerates the reduction of $\mathbf{A g}$ oxide by hydrogen. The degree of reduction of (a) palladium oxide in a PdO film on $\mathrm{Pd}(111)$ (black) and $\mathrm{PdO}_{x}$ islands surrounded by $\mathrm{Ag}(111)-\mathrm{O}$ (red) and (b) silver oxide in the $\mathrm{Ag}(111)-\mathrm{p}(4 \times 4) \mathrm{O}$ surface oxide (black) and in the silver oxide in the presence of $\mathrm{PdO}_{x}$ islands with their cumulative exposure to molecular hydrogen at $300 \mathrm{~K}$. The oxidation states of palladium and silver were monitored by the integrated intensities of their respective $3 d_{5 / 2}$ XPS peaks. The pressure of molecular hydrogen for each reduction step is detailed in the Supplementary Information. All data are normalized to the integrated area of the oxide peaks after the oxidation treatment (Supplementary Figs. 1-4, Supplementary Notes 1-3). required to most effectively use the bifunctional character of alloy catalysts.

Prior studies have demonstrated that the interface between metal nanoparticles and the metal oxide support can affect chemical behavior by the creation of specific active sites ${ }^{12-18}$ and direct migration or "spillover"19 of reactive species created on one phase to a neighboring phase of differing reactivity ${ }^{19-25}$. The metal/oxide support interface can significantly restructure in reactive gas environments on a short timescale of minutes and long length scales of microns ${ }^{26}$. Catalyst activity can be significantly modified by interface restructuring including changes in coordination environment ${ }^{27}$, catalyst encapsulation ${ }^{28}$, and metal component transport and alloying ${ }^{29-33}$.

Similarly, metal/metal interfaces of alloy nanoparticles can restructure under reactive gas conditions and promote intermediate migration. The interface can significantly reorganize by segregation and dissolution of metal components ${ }^{34-36}$, structural rearrangement ${ }^{37}$, and formation of oxide/oxide interfaces in reactive gas environments ${ }^{10,11}$. The migration of intermediates via hydrogen atom spillover across a bimetallic interface has been demonstrated for several metal/metal interfaces ${ }^{38-41}$. The behavior of bimetallic oxide interfaces in promoting the migration of intermediates, though, may even be more complex than for metal/oxide support or metal/metal interfaces, as we examine in this paper.

Herein, we demonstrate that synergistic effects arising from interfacial energetics dramatically alter reactivity associated with hydrogen atom migration across the palladium oxide/silver oxide interface produced from oxidation of the alloy, resulting in intermixing of metal atoms at the two-dimensional bimetallic oxide interface during the reactive process at room temperature. Specifically, intermixing of palladium and silver plays a critical role in accelerating the rate of reduction of oxidized $\operatorname{Ag}(111)$ by molecular hydrogen because of the presence of palladium oxide islands on the silver oxide surface. The increase in reactivity is attributed to the higher activity of palladium oxide for dissociating molecular hydrogen to produce hydrogen atoms, which can either (1) spillover directly onto the silver oxide or (2) react at the palladium oxide boundary with oxygen provided by silver oxide that is supplied to the palladium as palladium oxide is reduced. In parallel, the rate of reduction of palladium oxide is retarded as silver is incorporated into its structure at the interface. The high mobility of silver and silver oxide complexes, even at room temperature, is an important factor in this mechanism ${ }^{42-44}$. The intermixing of palladium and silver that accompanies the acceleration of silver oxide reduction demonstrates the complexity of synergistic effects in catalysis, especially when reducible oxides are involved.

\section{Results}

Generation of palladium and silver oxide surfaces. The reactivity of molecular hydrogen with a thin film of palladium oxide (PdO) on $\mathrm{Pd}(111)$, silver oxide $(\mathrm{Ag}(111)-\mathrm{p}(4 \times 4) \mathrm{O})$ on $\mathrm{Ag}(111)$ and palladium oxide $\left(\mathrm{PdO}_{x}\right)$ on $\mathrm{Ag}(111)$ surfaces was compared using ambient-pressure X-ray photoelectron spectroscopy (AP$\mathrm{XPS}$ ). A palladium oxide (PdO) film was generated by oxidation of a single crystal of $\mathrm{Pd}(111)$ with molecular oxygen at $773 \mathrm{~K}$ and 2 Torr (Supplementary Fig. 1) ${ }^{45}$. Similarly, the surface oxide of silver $(\operatorname{Ag}(111)-\mathrm{p}(4 \times 4) \mathrm{O})$ was generated by oxidation of $\operatorname{Ag}(111)$ by molecular oxygen at $773 \mathrm{~K}$ and 2 Torr (Supplementary Fig. 2) ${ }^{46}$. Palladium oxide $\left(\mathrm{PdO}_{x}\right)$ islands surrounded by the surface oxide of $\operatorname{Ag}(111)$ were generated by deposition of 0.10 monolayers (ML) of palladium on $\mathrm{Ag}(111)$ followed by exposure to molecular oxygen at $377 \mathrm{~K}$ and 3 Torr for $25 \mathrm{~min}$ (Fig. 1, Supplementary Figs. 3, 4). 
a

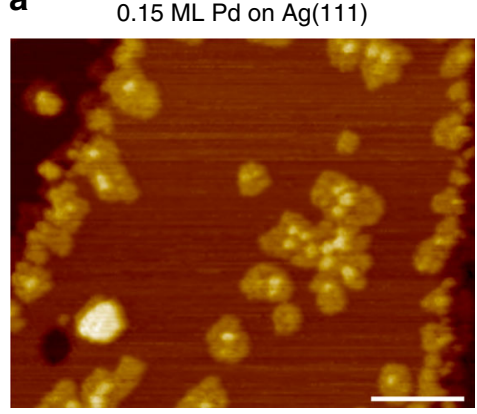

b

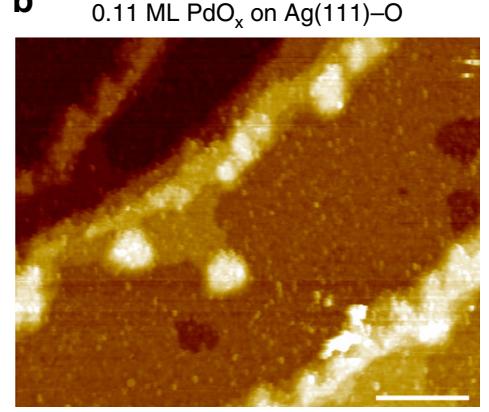

C Reduced $0.12 \mathrm{ML} \mathrm{PdO}_{\mathrm{x}}$ on $\mathrm{Ag}(111)$

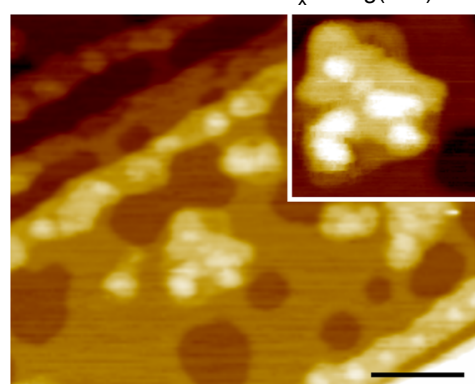

Fig. 2 Palladium-silver restructuring during oxidation and reduction. a-c A series of characteristic STM images of (a) as-deposited palladium on $\mathrm{Ag}$ (111), (b) after oxidation of (a) in 3 Torr of molecular oxygen at $425 \mathrm{~K}$, and (c) subsequent reduction by molecular hydrogen at $300 \mathrm{~K}$. $\mathbf{a}$, $\mathbf{b}$ The apparent height of the islands increases from single layer $(0.2 \mathrm{~nm})$ to multilayer structures $(0.9 \mathrm{~nm})$ upon oxidation. $\mathbf{b}, \mathbf{c}$ After reduction, the apparent height of the islands decreases to $0.6 \mathrm{~nm}$ and etch pits form on the silver attributed to silver oxide decomposition and silver etching and subsequent intermixing into the palladium islands. $\mathbf{c}$ Inset shows a high-resolution image of the intermixed palladium-silver island. Line scans of the islands and pits are detailed in Supplementary Fig. 6. STM details: (a) $V_{\text {sample }}=2.00 \mathrm{~V}, I_{\text {setpoint }}=0.300 \mathrm{nA},(\mathbf{b}) V_{\text {sample }}=1.50 \mathrm{~V}, I_{\text {setpoint }}=0.300 \mathrm{nA},(\mathbf{c}) V_{\text {sample }}=1.90 \mathrm{~V}, I_{\text {setpoint }}=$ $0.250 \mathrm{nA}$. Scale bars: $40 \mathrm{~nm}$.

a

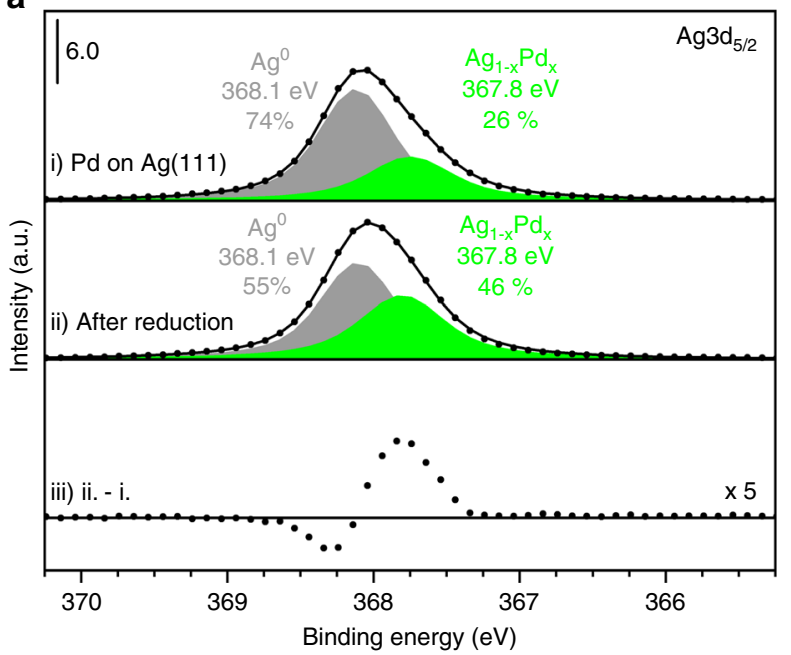

b

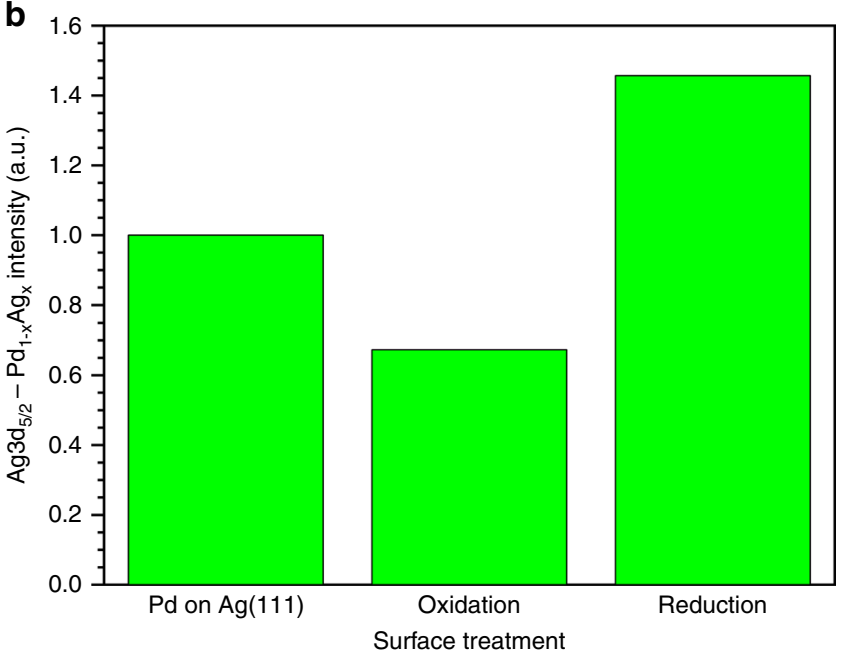

Fig. 3 Palladium-silver intermixing during reduction by hydrogen. a Palladium-silver intermixing occurs after reduction of $\mathrm{PdO} \mathrm{O}_{x}$ on $\mathrm{Ag}(111)$ as evidenced by the increased $\mathrm{Ag}_{1-x} \mathrm{Pd}_{x}$ alloy peak in the $\mathrm{Ag} 3 \mathrm{~d}_{5 / 2}$ region (green) using $\mathrm{AP}-\mathrm{XPS}$. Spectra are for (i) as-deposited $0.10 \mathrm{ML}$ palladium on $\mathrm{Ag}(111)$, (ii) after reduction of $\mathrm{PdO}_{x}$ on $\mathrm{Ag}(111)$, and (iii) the difference trace (ii-i) to better illustrate the increase in the $\mathrm{PdAg}$ alloy signal. $\mathbf{b}$ The formation of $\mathrm{PdO} \mathrm{O}_{x}$ on $\mathrm{Ag}$ (111) decreases the palladium-silver interface area because of palladium dewetting while the reduction of $\mathrm{PdO}_{x}$ on $\mathrm{Ag}$ (111) induces palladium-silver intermixing as illustrated by the increase in the $\mathrm{Ag}_{1-x} \mathrm{Pd}_{x}$ alloy peak.

Palladium dewetting during palladium-silver oxidation. Palladium dewets the surface when the single layer palladium islands on $\operatorname{Ag}(111)$ are oxidized to form domains of silver surface oxide and multilayer $\mathrm{PdO}_{x}$ (Figs. 2a, b, 3). Initially, the palladium forms predominantly single layer islands with an apparent height of 0.2 $\mathrm{nm}$, as revealed by scanning tunneling microscopy (STM) (Fig. 2a). During oxidation, $\mathrm{PdO}_{x}$ islands form condensed particles with apparent heights of $0.9 \mathrm{~nm}$ (Fig. 2b). Accordingly, there is a $30 \%$ decrease in the $\mathrm{X}$-ray photoelectron $\mathrm{Pd} 3 \mathrm{~d}_{5 / 2}$ total signal relative to palladium on $\operatorname{Ag}(111)$ before oxidation, which is attributed to the attenuation of subsurface palladium in the multilayer structures (Supplementary Table 3). The palladium dewetting is associated with a $33 \%$ decrease in the $\mathrm{Ag} 3 \mathrm{~d}_{5 / 2} \mathrm{PdAg}$ alloy signal relative to unoxidized palladium on $\operatorname{Ag}(111)$ because of a decreased palladium-silver interface area (Fig. 3b, Supplementary Table 3). Similarly, the segregation of palladium oxide and silver oxide occurs for the oxidation of a $\operatorname{Pd}_{75} \mathrm{Ag}_{25}(100)$ bulk alloy 47 .
Palladium oxide catalyzes the reduction of silver oxide. The key experimental observations that demonstrate hydrogen spillover from islands of $\mathrm{PdO}_{x}$ onto the surrounding silver oxide surface and the synergistic effects that drive this phenomenon are as follows:

(1) Molecular hydrogen is readily activated by palladium oxide. Films of palladium oxide $(\mathrm{PdO})$ on metallic palladium $(\mathrm{Pd}$ (111)) were readily reduced by molecular hydrogen, commencing at cumulative molecular hydrogen exposures of approximately $10^{3}$ monolayers (equivalent) (Fig. 1a, black curve). The reduction of $\mathrm{PdO}$ by molecular hydrogen is rapid and autocatalytic, accelerating with time at constant molecular hydrogen pressure ${ }^{48}$. The reaction proceeds through an initial slow rate of molecular hydrogen dissociation on $\mathrm{PdO}$ to form hydroxyls and atomic hydrogen, which initiates the reduction of palladium oxide to create a defective surface, which reduces more rapidly based on prior literature ${ }^{48}$. 
(2) $\mathrm{Ag}(111)-\mathrm{p}(4 \times 4)-\mathrm{O}$ is not reduced by molecular hydrogen. Cumulative exposures of up to $10^{7}$ monolayers of molecular hydrogen cause no observable reduction of surface oxygen (Fig. 1b, black curve), consistent with the low rate of molecular hydrogen dissociation on silver ${ }^{49,50}$.

(3) $\mathrm{PdO}_{x}$ on the $\operatorname{Ag}(111)$ surface catalyzes the reduction of the supporting silver oxide by molecular hydrogen. The presence of $\mathrm{PdO}_{x}$ on $\mathrm{Ag}(111)$ increases the rate of reduction of silver oxide with molecular hydrogen by more than $10^{4}$ at $300 \mathrm{~K}$ (Fig. 1b, red curve). Therefore, $\mathrm{PdO}_{x}$ must activate molecular hydrogen, catalyzing the reduction of the surrounding silver oxide surface at $300 \mathrm{~K}$ (Fig. 1a). The onset of reduction of the $\mathrm{PdO}_{x}$ on $\mathrm{Ag}(111)$ occurs at the same molecular hydrogen exposure as does palladium oxide reduction on the $\mathrm{PdO}$ surface, which indicates a similar rate for initial molecular hydrogen dissociation on both. $\mathrm{PdO}_{x}$ is reduced at a much slower rate than occurs on $\mathrm{PdO}$, which will be discussed later in context of structural changes during the reaction (Fig. 1a, red curve). There is clear preference for molecular hydrogen reduction of the surrounding silver oxide rather than reduction of the $\mathrm{PdO}_{x}$.

Intermediate migration across palladium-silver interface. The high reactivity of the silver oxide surrounding the $\mathrm{PdO}_{x}$ islands is attributed to molecular hydrogen dissociation on $\mathrm{PdO}_{x}$ followed by migration of atomic hydrogen across the palladium-silver interface and reduction of silver oxide. The preferential reduction of the silver oxide surrounding the $\mathrm{PdO}_{x}$ islands (Fig. 1b, red) occurs at a rate similar to that of the PdO film (Fig. 1a, black), which suggests that the transport and reaction of atomic hydrogen onto the silver oxide must be nearly equal to its rate of generation on the $\mathrm{PdO}_{x}$. A detailed investigation of the intrinsic kinetics of silver oxide reduction by hydrogen atoms is warranted. Molecular hydrogen reduction of $\mathrm{PdO}$ on $\mathrm{Pd}(111)$ and palladium oxide $^{48,51}$ occurs via the activation of molecular hydrogen to form atomic hydrogen (and hydroxyls). Hydroxyl migration from $\mathrm{PdO}_{x}$ to silver oxide and reaction with silver oxide would lead to no net reduction of silver oxide and therefore is implausible. The rate of migration of intermediates across the $\mathrm{PdO}_{x}$ - silver oxide interface is expected to be atomic hydrogen $\approx$ hydroxyls $>$ atomic oxygen based on their respective binding energies on palladium, silver, and palladium-silver alloy sites ${ }^{52-61}$. However, it is quite possible that atomic oxygen transfers from the $\mathrm{Ag}(111)-\mathrm{O}$ (perhaps via silver oxide complexes) to the $\mathrm{PdO}_{x}$ as it is reduced, significantly contributing to the rate of reduction of the silver oxide because it is known that short $\mathrm{Ag}-\mathrm{O}$ chains are quite mobile on $\operatorname{Ag}(110)$, and the reduction of $\operatorname{Ag}(111)-\mathrm{p}(4 \times 4) \mathrm{O}$ by carbon monoxide generates mobile silver atoms ${ }^{42-44}$. Direct hydroxyl migration from silver oxide to $\mathrm{PdO}_{x}$ to mitigate the rate of reduction of the $\mathrm{PdO}_{x}$ is unlikely, since it necessitates the formation of hydroxyls on silver oxide by the direct reaction of silver oxide with molecular hydrogen. Therefore, we propose that silver oxide reduction is initiated by atomic hydrogen migration from $\mathrm{PdO}_{x}$ to silver oxide and that the reduction proceeds by hydrogen atom migration from $\mathrm{PdO}_{x}$ to silver oxide. The net rate of reduction of the $\mathrm{PdO}_{x}$ may be mitigated by migration of atomic oxygen from silver oxide to partially reduced $\mathrm{PdO}_{x}$. The effect of the palladium surface coverage, distribution, and oxidation state on the reduction of silver oxide is currently under investigation.

Palladium-silver intermixing during reduction by hydrogen. Intermixing of palladium and silver occurs as a consequence of the reduction of the $\mathrm{PdO}_{x}$ on $\mathrm{Ag}(111)-\mathrm{O}$ by molecular hydrogen, based on both $\mathrm{X}$-ray photoelectron spectroscopy and scanning tunneling microscopy (Figs. 2b, c, 3). The amount of PdAg alloy relative to palladium deposited on $\operatorname{Ag}(111)$ increases after the silver oxide reduction is completed (Fig. 3). Associated with reduction is also the creation of etch pits on the surface. These pits are one-layer deep and cover $38 \%$ of the surface (Fig. 2c, Supplementary Fig. 5, Supplementary Table 4, Supplementary Note 4$)$. The combined area of these etch pits greatly exceeds that expected from reduction of the $\mathrm{Ag}(111)-\mathrm{p}(4 \times 4)-\mathrm{O}$ itself, which is known to be only $17 \%$ of the surface (Supplementary Table 4$)^{43}$. Thus, the larger fraction of etch pits observed following reduction of palladium oxide/silver oxide is attributed to silver migration to and intermixing into palladium islands during reduction. No measurable changes in morphology of unoxidized, metallic palladium on $\mathrm{Ag}(111)$ are observed after exposure to molecular hydrogen at $300 \mathrm{~K}$ (Supplementary Fig. 7). Indeed, this intermixing appears to be energetically stable, as it has been observed that heating of palladium islands on $\operatorname{Ag}(111)$ is necessary for extensive intermixing ${ }^{62}$. Hence, the intermixing at room temperature must be facilitated by reduction of the palladium and silver oxides (Supplementary Table 4). In support of this intermixing, STM reveals that the islands are significantly higher after reduction of the oxides than they were prior to oxidation (Fig. 2c).

\section{Discussion}

In this work, synergistic effects that dramatically alter reactivity at an oxide/oxide interface of an alloy surface are demonstrated: intermixing of metal atoms at the interface during a reactive process associated with the spillover of a reactive intermediate from one phase to another. The intermixing of palladium and silver occurs during the reduction of oxidized $\mathrm{Ag}(111)$ by molecular hydrogen due to the presence of $\mathrm{PdO}_{x}$ islands.

Previously, migration of hydrogen atoms has been demonstrated away from single metal atoms and metal islands to either a metal or metal oxide host; ${ }^{19-23,38-41,63}$ however, intermixing and reconstruction during reaction was not evident. For example, single palladium atoms in copper promote molecular hydrogen dissociation on palladium and subsequent migration to the copper $^{38}$. Migration of hydrogen atoms also occurs across interfaces between metal particles, e.g. cobalt, and metal surfaces, e.g. copper $^{39}$. Furthermore, migration between metal and metal oxides phases has also been reported for hydrogen atoms ${ }^{19}$. For example, molecular hydrogen dissociation at a site spanning single palladium atoms on iron oxide $\left(\mathrm{Fe}_{3} \mathrm{O}_{4}(001)\right)$ forms hydroxyls on the oxide via a heterolytic bond breaking process ${ }^{23}$. Migration of intermediates across interfaces between oxide islands of titania and ceria $\left(\mathrm{TiO}_{2}\right.$ and $\left.\mathrm{CeO}_{2}\right)$ formed on gold and copper has also been demonstrated ${ }^{64,65}$. Similarly, copper oxidation was promoted by ceria $\left(\mathrm{CeO}_{2}\right)$ islands, indicating that oxygen transport across interfaces is also possible ${ }^{66}$. The intermixing of metal atoms at the interface was not observed in any of these cases.

The acceleration of silver oxide reduction, which is accompanied by intermixing of palladium and silver described here demonstrates the complexity of synergistic effects in alloy nanoparticle catalysis, especially when reducible oxides are involved. Such intermixing can alter reaction rates and, therefore, must be considered in modeling such behavior.

The dramatic enhancement of the rate of silver surface oxide reduction due to the presence of $\mathrm{PdO}_{x}$ islands is accompanied by intermixing of palladium and silver. The facile intermixing of metals involved during a reaction process on a model alloy surface demonstrates the complexity of synergistic effects in alloy nanoparticle catalysis. Such intermixing, which can alter reaction rates, has not previously been established in the context of reactant migration across the interface between two different 
reducible oxides formed from oxidation of an alloy. This study clearly demonstrates that such intermixing must be considered in modeling the behavior of complex catalyst materials.

\section{Methods}

Sample preparation. The $\mathrm{Pd}(111)$ single crystal was cleaned by several cycles of argon ion $\left(\mathrm{Ar}^{+}\right)$sputtering $(10-20 \mathrm{~min}, 1 \mathrm{keV})$ and annealing $(5 \mathrm{~min}, 1000 \mathrm{~K})$. The $\mathrm{Ag}(111)$ single crystal was cleaned by several cycles of argon ion $\left(\mathrm{Ar}^{+}\right)$sputtering (10-20 min, $2 \mathrm{keV})$, molecular oxygen treatment $\left(1 \times 10^{-5}\right.$ Torr, $\left.5 \mathrm{~min}, 500 \mathrm{~K}\right)$ and annealing $(5 \mathrm{~min}, 800 \mathrm{~K})$. Palladium was evaporated and deposited on the $\mathrm{Ag}(111)$ crystal when the sample was $300 \mathrm{~K} . \mathrm{Pd}(111)$ and $\mathrm{Ag}(111)$ were oxidized in 2 Torr of molecular oxygen at $773 \mathrm{~K}$ for $5 \mathrm{~min}$ while palladium on $\mathrm{Ag}(111)$ was oxidized in 3 Torr of molecular oxygen at $373 \mathrm{~K}$ for $25 \mathrm{~min}$.

AP-XPS details. AP-XPS experiments were performed at beamline 11.0.2 of the Advanced Light Source at the Lawrence Berkeley National Laboratory. Prior to experiments the chamber was cleaned using a conventional bake-out and between experiments the chamber was repeatedly purged with 2 Torr of molecular oxygen to reduce contamination from the displacement of gases adsorbed to the chamber walls during high-pressure doses. All spectra were recorded in ultra-high vacuum (UHV) in order to eliminate beam-induced reactivity that can occur when a significant gas pressure is present.

A photon energy of $800 \mathrm{eV}$ was used to take a survey scan to check for contamination before acquiring high-resolution spectra. Photon energies of $535 \mathrm{eV}$ for Pd3d and $568 \mathrm{eV}$ for Ag3d were used to produce photoelectrons with kinetic energies around $200 \mathrm{eV}$ for high-resolution spectra. The binding energies reported are referenced to the Fermi level as measured after each spectrum. The data was fitted after a Shirley ${ }^{67}$ background subtraction and normalization to the background at the low binding energy side of the peaks. The $\mathrm{Ag}(111)$ and $\mathrm{Pd} / \mathrm{Ag}$ (111) spectra were fitted with a Doniach-Šunjić function ${ }^{68}$ convoluted with a Gaussian function and the $\operatorname{Pd}(111)$ spectra were fitted with a Mahan function ${ }^{69}$ convoluted with a Gaussian function.

STM details. STM experiments were perform using an Omicron VT-STM-XA 650 system (UHV Multiprobe). All samples were prepared in the preparation chamber of a lab-based ambient-pressure photoelectron spectroscopy system. The samples were then transferred in a vacuum suitcase (base pressure $<1.0 \times 10^{-9}$ Torr) for imaging in the UHV multiprobe surface analysis system.

\section{Data availability}

All the data that support the findings of this study are available within the paper and its Supplementary Information, or from the corresponding author on reasonable request.

Received: 14 February 2020; Accepted: 16 March 2020;

Published online: 15 April 2020

\section{References}

1. Sinfelt, J. H. Catalysis by alloys and bimetallic clusters. Acc. Chem. Res. 10, 15-20 (1977).

2. Lu, Q. et al. Highly porous non-precious bimetallic electrocatalysts for efficient hydrogen evolution. Nat. Commun. 6, 6567 (2015).

3. Savadogo, O. \& Ndzebet, E. Hydrogen evolution reaction (h.e.r.) in an acidic or basic medium on nickel electrodeposited with $\mathrm{PW}_{12} \mathrm{O}_{40}{ }^{3-}$ and $\mathrm{Cu}^{2+}$. J. Appl. Electrochem. 23, 915-921 (1993).

4. Graetz, J. New approaches to hydrogen storage. Chem. Soc. Rev. 38, 73-82 (2009).

5. Wei, Z., Sun, J., Li, Y., Datye, A. K. \& Wang, Y. Bimetallic catalysts for hydrogen generation. Chem. Soc. Rev. 41, 7994-8008 (2012).

6. Wang, C.-Y., Chang, C.-W., Wu, Y.-J. \& Lueking, A. D. Observation and simulation of hydrogen storage via spillover. Curr. Opin. Chem. Eng. 21, 116-121 (2018).

7. Tréglia, G. et al. Alloy surfaces: segregation, reconstruction and phase transitions. Comput. Mater. Sci. 15, 196-235 (1999).

8. Divi, S. \& Chatterjee, A. Generalized nano-thermodynamic model for capturing size-dependent surface segregation in multi-metal alloy nanoparticles. RSC Adv. 8, 10409-10424 (2018).

9. Christensen, A. et al. Phase diagrams for surface alloys. Phys. Rev. B 56, 5822-5834 (1997).

10. Zafeiratos, S., Piccinin, S. \& Teschner, D. Alloys in catalysis: phase separation and surface segregation phenomena in response to the reactive environment. Catal. Sci. Technol. 2, 1787-1801 (2012).

11. Wachs, I. E. \& Routray, K. Catalysis science of bulk mixed oxides. ACS Catal. 2, 1235-1246 (2012).
12. Haruta, M., Yamada, N., Kobayashi, T. \& Lijima, S. Gold catalysts prepared by coprecipitation for low-temperature oxidation of hydrogen and of carbon monoxide. J. Catal. 115, 301-309 (1989).

13. Haruta, $\mathrm{M}$. et al. Low-temperature oxidation of $\mathrm{CO}$ over Gold supported on $\mathrm{TiO}_{2}, \alpha-\mathrm{Fe}_{2} \mathrm{O}_{3}$, and $\mathrm{Co}_{3} \mathrm{O}_{4}$. J. Catal. 144, 175-192 (1993).

14. Green, I. X., Tang, W., Neurock, M. \& Yates, J. T. Spectroscopic observation of dual catalytic sites during oxidation of $\mathrm{CO}$ on a $\mathrm{Au} / \mathrm{TiO}_{2}$ catalyst. Science 333, 736-739 (2011).

15. Liu, Z. P., Gong, X. Q., Kohanoff, J., Sanchez, C. \& Hu, P. Catalytic role of metal oxides in gold-based catalysts: a first principles study of $\mathrm{CO}$ oxidation on $\mathrm{TiO}_{2}$ supported Au. Phys. Rev. Lett. 91, 266102 (2003).

16. Molina, L. M. \& Hammer, B. Some recent theoretical advances in the understanding of the catalytic activity of Au. Appl. Catal. A Gen. 291, 21-31 (2005).

17. Molina, L. M. \& Hammer, B. Theoretical study of $\mathrm{CO}$ oxidation on $\mathrm{Au}$ nanoparticles supported by $\mathrm{MgO}(100)$. Phys. Rev. B. 69, 155424 (2004).

18. Farfan-Arribas, E., Biener, J., Friend, C. M. \& Madix, R. J. Reactivity of methanol on $\mathrm{TiO}_{2}$ nanoparticles supported on the $\mathrm{Au}(111)$ surface. Surf. Sci. 591, 1-12 (2005)

19. Prins, R. Hydrogen spillover. Facts and fiction. Chem. Rev. 112, 2714-2738 (2012).

20. Levy, R. B. \& Boudart, M. The kinetics and mechanism of spillover. J. Catal. 32, 304-314 (1974).

21. Park, J. et al. Investigation of the support effect in atomically dispersed Pt on $\mathrm{WO}_{3-\mathrm{x}}$ for utilization of $\mathrm{Pt}$ in the hydrogen evolution reaction. Angew. Chem. Int. Ed. 58, 16038-16042 (2019).

22. Karim, W. et al. Catalyst support effects on hydrogen spillover. Nature 541, 68-71 (2017).

23. Doudin, N. et al. Understanding heterolytic $\mathrm{H}_{2}$ cleavage and water-assisted hydrogen spillover on $\mathrm{Fe}_{3} \mathrm{O}_{4}(001)$-supported single palladium atoms. ACS Catal. 9, 7876-7887 (2019)

24. Hurst, N. W., Gentry, S. J., Jones, A. \& McNicol, B. D. Temperature programmed reduction. Catal. Rev. Sci. Eng. 24, 233-309 (1982).

25. Kung, H. H. (ed) in Surface Science and Catalysis Vol. 45, Ch. 6, 91-109 (Elsevier, Amsterdam, 1989).

26. Goodman, E. D. et al. Catalyst deactivation via decomposition into single atoms and the role of metal loading. Nat. Catal. 2, 748-755 (2019).

27. DeRita, L. et al. Structural evolution of atomically dispersed Pt catalysts dictates reactivity. Nat. Mater. 18, 746-751 (2019).

28. Matsubu, J. C. et al. Adsorbate-mediated strong metal-support interactions in oxide-supported Rh catalysts. Nat. Chem. 9, 120-127 (2017).

29. Isaacs, B. H. \& Petersen, E. E. The effect of drying temperature on the temperature-programmed reduction profile of a platinum/rhenium/alumina catalyst. J. Catal. 77, 43-52 (1982).

30. Wagstaff, N. \& Prins, R. Alloy formation and metal oxide segregation in PtRe/ $\gamma-\mathrm{Al}_{2} \mathrm{O}_{3}$ catalysts as investigated by temperature-programmed reduction. $J$. Catal. 59, 434-445 (1979).

31. Ziemecki, S. B., Jones, G. A. \& Michel, J. B. Surface mobility of $\mathrm{Re}_{2} \mathrm{O}_{7}$ in the system $\mathrm{Re}^{7+} \mathrm{Pd}^{0} / \gamma-\mathrm{Al}_{2} \mathrm{O}_{3}$. J. Catal. 99, 207-217 (1986).

32. Rønning, M., Gjervan, T., Prestvik, R., Nicholson, D. G. \& Holmen, A. Influence of pretreatment temperature on the bimetallic interactions in Pt-Re/ $\mathrm{Al}_{2} \mathrm{O}_{3}$ reforming catalysts studied by X-ray absorption spectroscopy. J. Catal. 204, 292-304 (2001).

33. Prestvik, R., Tøtdal, B., Lyman, C. E. \& Holmen, A. Bimetallic particle formation in $\mathrm{Pt}-\mathrm{Re} / \mathrm{Al}_{2} \mathrm{O}_{3}$ reforming catalysts revealed by energy-dispersive $\mathrm{X}$ ray spectrometry in the analytical electron microscope. J. Catal. 176, 246-252 (1998).

34. Zugic, B. et al. Dynamic restructuring drives catalytic activity on nanoporous gold-silver alloy catalysts. Nat. Mater. 16, 558-564 (2017).

35. Tao, F. et al. Reaction-driven restructuring of Rh-Pd and Pt-Pd core-shell nanoparticles. Science 322, 932-934 (2008).

36. Zugic, B. et al. Evolution of steady-state material properties during catalysis: Oxidative coupling of methanol over nanoporous Ag0.03Au0.97. J. Catal. 380, 366-374 (2019).

37. Eren, B. et al. Activation of $\mathrm{Cu}(111)$ surface by decomposition into nanoclusters driven by CO adsorption. Science 351, 475-478 (2016).

38. Tierney, H. L., Baber, A. E., Kitchin, J. R. \& Sykes, E. C. H. Hydrogen dissociation and spillover on individual isolated palladium atoms. Phys. Rev. Lett. 103, 246102 (2009).

39. Lewis, E. A., Marcinkowski, M. D., Murphy, C. J., Liriano, M. L. \& Sykes, E. C. $\mathrm{H}$. Hydrogen dissociation, spillover, and desorption from $\mathrm{Cu}$-supported $\mathrm{Co}$ nanoparticles. J. Phys. Chem. Lett. 5, 3380-3385 (2014).

40. Goodman, D. W., Yates, J. T. \& Peden, C. H. F. The reaction of atomic copper with chemisorbed hydrogen on ruthenium. Surf. Sci. 164, 417-424 (1985).

41. Yao, Y. \& Goodman, D. W. Direct evidence of hydrogen spillover from Ni to $\mathrm{Cu}$ on Ni-Cu bimetallic catalysts. J. Mol. Catal. A Chem. 383-384, 239-242 (2014). 
42. Langelaar, M. H., Breeman, M. \& Boerma, D. O. Mobility of Ag adatoms on $\mathrm{Ag}(100)$. Surf. Sci. 352-354, 597-601 (1996).

43. Klust, A. \& Madix, R. J. Mesoscopic restructuring and mass transport of metal atoms during reduction of the $\mathrm{Ag}(111)-\mathrm{p}(4 \times 4)-\mathrm{O}$ surface with CO. J. Chem. Phys. 126, 084707 (2007).

44. Barth, J. V., Zambelli, T., Wintterlin, J., Schuster, R. \& Ertl, G. Direct observation of mobility and interactions of oxygen molecules chemisorbed on the Ag(110) surface. Phys. Rev. B 55, 12902-12905 (1997).

45. Ketteler, G. et al. In situ spectroscopic study of the oxidation and reduction of $\operatorname{Pd}(111)$. J. Am. Chem. Soc. 127, 18269-18273 (2005).

46. Jones, T. E. et al. Thermodynamic and spectroscopic properties of oxygen on silver under an oxygen atmosphere. Phys. Chem. Chem. Phys. 17, 9288-9312 (2015).

47. Walle, L. E. et al. Surface composition of clean and oxidized $\mathrm{Pd}_{75} \mathrm{Ag}_{25}(100)$ from photoelectron spectroscopy and density functional theory calculations. Surf. Sci. 606, 1777-1782 (2012).

48. Martin, N. M. et al. Dissociative adsorption of hydrogen on PdO(101) studied by HRCLS and DFT. J. Phys. Chem. C 117, 13510-13519 (2013).

49. Mohammad, A. B., Lim, K. H., Yudanov, I. V., Neyman, K. M. \& Rösch, N. A computational study of $\mathrm{H}_{2}$ dissociation on silver surfaces: the effect of oxygen in the added row structure of $\mathrm{Ag}(110)$. Phys. Chem. Chem. Phys. 9, 1247-1254 (2007).

50. Mohammad, A. B., Yudanov, I. V., Lim, K. H., Neyman, K. M. \& Rösch, N. Hydrogen activation on silver: a computational study on surface and subsurface oxygen species. J. Phys. Chem. C. 112, 1628-1635 (2008).

51. Blanco-Rey, M., Wales, D. J. \& Jenkins, S. J. Mechanisms for $\mathrm{H}_{2}$ reduction on the $\mathrm{PdO}\{101\}$ surface and the $\mathrm{Pd}\{100\}-(\sqrt{5} \times \sqrt{5}) \mathrm{R} 27^{\circ}$-O surface oxide. $J$. Phys. Chem. C. 113, 16757-16765 (2009).

52. Zhou, X.-L., White, J. M. \& Koel, B. E. Chemisorption of atomic hydrogen on clean and Cl-covered Ag(111). Surf. Sci. 218, 201-210 (1989).

53. Chen, B. W. J., Kirvassilis, D., Bai, Y. \& Mavrikakis, M. Atomic and molecular adsorption on $\mathrm{Ag}(111)$. J. Phys. Chem. C. 123, 7551-7566 (2019).

54. Nørskov, J. K., Abild-Pedersen, F., Studt, F. \& Bligaard, T. Density functional theory in surface chemistry and catalysis. Proc. Natl. Acad. Sci. 108, 937-943 (2011).

55. Løvvik, O. M. \& Olsen, R. A. Density functional calculations of hydrogen adsorption on palladium-silver alloy surfaces. J. Chem. Phys. 118, 3268-3276 (2003).

56. Kitchin, J. R., Reuter, K. \& Scheffler, M. Alloy surface segregation in reactive environments: first-principles atomistic thermodynamics study of $\mathrm{Ag}_{3} \mathrm{Pd}(111)$ in oxygen atmospheres. Phys. Rev. B 77, 075437 (2008).

57. Conrad, H., Ertl, G. \& Latta, E. E. Adsorption of hydrogen on palladium single crystal surfaces. Surf. Sci. 41, 435-446 (1974).

58. Bange, K., Madey, T. E., Sass, J. K. \& Stuve, E. M. The adsorption of water and oxygen on $\operatorname{Ag}(110)$ : a study of the interactions among water molecules, hydroxyl groups, and oxygen atoms. Surf. Sci. 183, 334-362 (1987).

59. Mitsui, T., Rose, M. K., Fomin, E., Ogletree, D. F. \& Salmeron, M. A scanning tunneling microscopy study of the reaction between hydrogen and oxygen to form water on $\mathrm{Pd}(111)$. J. Chem. Phys. 117, 5855-5858 (2002).

60. Fogelberg, J. \& Petersson, L.-G. Kinetic modelling of the $\mathrm{H}_{2}-\mathrm{O}_{2}$ reaction on Pd and of its influence on the hydrogen response of a hydrogen sensitive $\mathrm{Pd}$ metal-oxide-semiconductor device. Surf. Sci. 350, 91-102 (1996).

61. Wang, G.-C., Tao, S.-X. \& Bu, X.-H. A systematic theoretical study of water dissociation on clean and oxygen-preadsorbed transition metals. J. Catal. 244, 10-16 (2006).

62. Van Spronsen, M. A. et al. Dynamics of surface alloys: rearrangement of $\mathrm{Pd} / \mathrm{Ag}(111)$ induced by $\mathrm{CO}$ and $\mathrm{O}_{2}$. J. Phys. Chem. C 123, 8312-8323 (2019).

63. Boucher, M. B. et al. Single atom alloy surface analogs in $\mathrm{Pd}_{0.18} \mathrm{Cu}_{15}$ nanoparticles for selective hydrogenation reactions. Phys. Chem. Chem. Phys. 15, 12187-12196 (2013).

64. Rodriguez, J. A. et al. Activity of $\mathrm{CeO}_{x}$ and $\mathrm{TiO}_{x}$ nanoparticles grown on $\mathrm{Au}(111)$ in the water-gas shift reaction. Science 318, 1757-1760 (2007).
65. Rodriguez, J. A. et al. Inverse oxide/metal catalysts in fundamental studies and practical applications: a perspective of recent developments. J. Phys. Chem. Lett. 7, 2627-2639 (2016).

66. Yang, F. et al. $\mathrm{CO}$ oxidation on inverse $\mathrm{CeO}_{\mathrm{x}} / \mathrm{Cu}(111)$ catalysts: high catalytic activity and ceria-promoted dissociation of $\mathrm{O}_{2}$. J. Am. Chem. Soc. 133, 3444-3451 (2011).

67. Shirley, D. A. High-resolution X-ray photoemission spectrum of the valence bands of gold. Phys. Rev. B 5, 4709-4714 (1972).

68. Doniach, S. \& Šunjić, M. Many-electron singularity in X-ray photoemission and X-ray line spectra from metals. J. Phys. C. Solid State Phys. 3, 285-291 (1970).

69. Mahan, G. D. Collective excitations in X-ray spectra of metals. Phys. Rev. B 11, 4814-4824 (1975)

\section{Acknowledgements}

The staff of beamline 11.0.2, especially Hendrik Bluhm, and the staff of the proximal probe facility at Center for Function Nanomaterials, especially Dario Stacchiola, Anibal Boscoboinik, and Xiao Tong, are gratefully acknowledged for their support. This research used resources of the Advanced Light Source, which is a DOE Office of Science User Facility under contract no. DE-AC02-05CH11231. This work was supported as part of the Integrated Mesoscale Architectures for Sustainable Catalysis, an Energy Frontier Research Center funded by the U.S. Department of Energy, Office of Science, Basic Energy Sciences under Award No. DE-SC0012573.

\section{Author contributions}

C.R.O, M.A.v.S., T. E., H.R.K., and J.O. performed the XPS experiments. C.R.O., F. X., and M. K. performed the STM experiments. C.R.O, M.A.v.S., and T.E. analyzed the data. C.R.O, M.S., R.J.M., and C.M.F wrote the manuscript.

\section{Competing interests}

The authors declare no competing interests.

\section{Additional information}

Supplementary information is available for this paper at https://doi.org/10.1038/s41467 020-15536-x.

Correspondence and requests for materials should be addressed to C.M.F.

Peer review information Nature Communications thanks the anonymous reviewers for their contribution to the peer review of this work. Peer reviewer reports are available.

Reprints and permission information is available at http://www.nature.com/reprints

Publisher's note Springer Nature remains neutral with regard to jurisdictional claims in published maps and institutional affiliations.

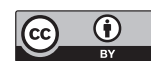

Open Access This article is licensed under a Creative Commons Attribution 4.0 International License, which permits use, sharing, adaptation, distribution and reproduction in any medium or format, as long as you give appropriate credit to the original author(s) and the source, provide a link to the Creative Commons license, and indicate if changes were made. The images or other third party material in this article are included in the article's Creative Commons license, unless indicated otherwise in a credit line to the material. If material is not included in the article's Creative Commons license and your intended use is not permitted by statutory regulation or exceeds the permitted use, you will need to obtain permission directly from the copyright holder. To view a copy of this license, visit http://creativecommons.org/ licenses/by/4.0/.

(C) The Author(s) 2020 